\title{
INSIDE THE PRACTICUM: CROSSING THE VISIONS OF THE ACTORS
}

\section{$\underline{\text { D. Lino }}^{1}, \underline{\text { C. Parente }}^{2}, \underline{\text { F. Vieira }}^{2}$}

${ }^{1}$ Institute Polytechnic of Lisbon, Higher School of Education/CIED/CIEC (PORTUGAL)

${ }^{2}$ University of Minho/Institute of Education/CIEC (PORTUGAL)

The roles and responsibilities of preschool teachers require a broad range of skills that include promoting child development, being sensitive and responsive to individual needs, working collaboratively with families and communities, and negotiating unexpected and challenging situations. The understanding of the practical training component is that of experiential learning supervised and reflected in real working context, in the case under study, at infants and toddlers and preschool classrooms. The supervision of practicum is understood as one of the most critical components of the formation of childhood educators. The main goal of this study is to understand the perceptions of the three actors of practicum: student teachers; university supervisors and cooperative teachers.

From this main goal the following objectives emerged:

(i) to know the models of supervision adopted by university supervisors and cooperative teachers;

(ii) to identify supervision strategies adopted by the university supervisor and the cooperative teacher that promote student teachers professional development;

(iii) to identify the critical factors that promote or hinder student teachers success;

(iv) to know the needs of other conditions and/or resources at the supervisory level.

The study is part of the interpretation paradigm, using for this reason a qualitative method. Data was collected through semi-structured interviews to 15 cooperative teachers, 15 university supervisors and 30 student teachers of preschool master programmes. A content analysis approach was used to analyse the data. To ensure confidentiality no information is disclosed without participants' consent and the interviews were transcribed and send to the participants for a final revision.The results reveal the key role of interactions and relations between student teachers and cooperative teachers and student teachers and university supervisors for the success at practicum, the importance of interconnecting theory and practice, reflection has a crucial role for student teacher's professional development, the need for more training in supervision for cooperative teachers and university supervisors.

keywords: practicum, supervision, professional development, early childhood teacher education. 